\title{
The Cost Efficiency of Water Utilities: When Does Public Ownership Matter?*
}

\author{
Silvia Pazzi ${ }^{\mathrm{a}}$, Emili Tortosa-Ausina ${ }^{\mathrm{tb}}$, Meryem Duygun $^{\mathrm{c}}$, and Simona Zambelli ${ }^{\mathrm{d}}$ \\ ${ }^{\mathrm{a}}$ School of Management, University of Leicester, Ken Edwards Building, University Road, Leicester, LE1 7RH, UK. \\ Email: sp505@le.ac.uk \\ ${ }^{b}$ Department d'Economia and Ivie, Universitat Jaume I and Ivie, Campus del Riu Sec, 12071 Castelló de la Plana, \\ Spain. Email: tortosa@uji.es \\ 'Business School, Hull University, Cottingham Road, Hull, North Humberside, HU6 7RX, UK. Email: \\ M.Duygun@hull.ac.uk \\ ${ }^{\mathrm{d}}$ Dipartimento di Scienze Aziendali, Università di Bologna, Via Capo di Lucca 34, Bologna, Italy. Email: \\ simona.zambelli@unibo.it
}

May 26, 2016

\begin{abstract}
This study explores the impact of different ownership types on the efficiency of water utilities. Theories and evidence have shown a puzzling relationship between ownership and performance. Moreover, relatively recent contributions (Andrews et al., 2011) have argued that this relationship can be further convoluted by the effect of organisational and environmental variables. The current study aims to contribute to this literature by providing some empirical evidence for Italy, by proposing a methodology that combines nonparametric efficiency estimation and cluster analysis. Our main findings indicate that privately owned utilities indirectly controlled by a public organisation reach the highest level of efficiency but, when size and geographical location enter the analysis, ownership has a stronger significant effect on efficiency, and mixed utilities gain higher cost efficiency. Therefore, we may conclude that administrative reforms about privatisation and the institutional setting should consider a set of variables that characterise each individual organisation.
\end{abstract}

Keywords: efficiency, geographical location, ownership, size, water utilities.

JEL classification: $\mathrm{H} 4, \mathrm{H} 7, \mathrm{H} 83$.

Communications to: Emili Tortosa-Ausina, Department of Economics and Ivie, Universitat Jaume I, Campus del Riu Sec, 12071 Castelló de la Plana, Spain. Tel.: +34 964387168, e-mail: tortosa@uji.es.

\footnotetext{
*All authors wish to thank Diego Prior and Germà Bel for helpful and constructive discussion, as well as the comments by participants at the Regional Studies Association Early Career Conference 2013 (Manchester, UK), XXI Encuentro de Economía Pública 2014 (Girona, Spain), and the 37th European Accounting Association Annual Congress 2014 (Tallinn, Estonia). Emili Tortosa-Ausina acknowledges the financial support of Ministerio de Economía y Competitividad (ECO2014-55221-P), Universitat Jaume I (P1.1B2014-17) and Generalitat Valenciana (ACOMP/2014/283 and PROMETEOII/2014/046).

${ }^{\dagger}$ Contact author.
} 


\section{INTRODUCTION}

In recent decades waves of administrative reforms have been implemented to improve local public services performance and cope with increasing constraints on financial resources. In this scenario, devolution and changes in ownership structure have occurred as a solution to public sector inefficiencies (Guy et al., 1996; Pollitt and Bouckaert, 2011; Savas, 2000; Shaw and Munday, 1999). Several scholars have investigated whether and how ownership affects performance, in order to find the most efficient, effective and fair way to deliver public services. The persistence of this issue in the literature can be motivated by different theoretical perspectives, puzzling empirical results and the acknowledgement that the link between ownership and performance is further complicated by the existence of 'moderators' such as organisational and environmental characteristics of the services provided (Andrews et al., 2011).

The extent of the debate about the ownership of public service production has been exacerbated by a wide acceptance of neo-liberal and New Public Management policies (Osborne and Gaebler, 1992; Hood, 1991) rooted in the Public Choice theory (Niskanen, 1971). According to this perspective, competition represents a solution to overcome public overproduction and inefficiency. Therefore it is assumed that governments, at any level, should privatise and contract-out services in order to achieve technical and cost efficiency. Ultimately this process would shift the ownership of service providers from the public to the private sector.

Along with Public Choice theory, other theoretical perspectives have dealt with issues regarding service delivery choices. First, Williamson $(1979,1999)$ suggests that transactions cost and monitoring can play an important role in the choice to externalise services. In particular, this approach suggests that when transaction costs are low, privatisation can lead to cost savings. Second, property rights theory (Demsetz, 1967) advocates that private ownership can lead to higher performance, due to better defined property rights and incentives to monitor and control the managers' behaviour. Third, the theory of incomplete contracts (Hart and Moore, 1990) suggests that privatisation could reduce costs, but without an adequate incentive system, it can also lower services' quality. In recent years several studies, such as Bel and Fageda (2010), Warner and Hefetz (2008), and Bel et al. (2014), among others, have highlighted the popularity of alternative ownership structures that combine public and private capital—such as mixed companies and public-private partnerships. Therefore these new types of organisations can challenge even more the relationship between ownership and performance (Vining and Weimer, ming). 
Empirical evidence on the relationship between ownership and performance has been reviewed by recent studies, such as Andrews et al. (2011) and Bel et al. (2010). Andrews et al. (2011) review thirty-one studies examine the link between 'publicness'(Bozeman, 1987) and performance in a wide range of public services. Bel et al. (2010) conduct meta-analysis of twenty-seven studies comparing the costs of public and private production in solid waste services and water distribution. Both of these extensive reviews reveal that there is no systematic evidence supporting the superiority of either public or private production for delivering public services. These studies suggest that performance and efficiency seems to be affected by other factors apart from ownership, such as transaction costs, economies of scale, regulation, governance, or the environment. Andrews et al. (2011) refer to these factors as 'moderators' of the relationship between ownership and performance.

In light of the literature, this study investigates whether ownership structure has a significant effect on the cost efficiency of water service utilities when 'moderators' such as size and geographical features are simultaneously considered. The empirical evidence is based on a sample of Italian water utilities from 2008 to 2011.

In this regard, Italy represents an ideal geographical case study given a highly heterogeneity in the ownership structures, size and environmental features of the water utilities operating in this country. Moreover, attention to Italian water utilities can be further motivated by three main reasons. First, in recent years the Italian water industry has been at the centre of a debate about the possibility of liberalisation (Massarutto et al., 2008). Second, in 2011 the legislator modified the multilevel governance of the industry by abolishing the so-called "Autorità d'Ambito Ottimale"("optimal area authority"), more popularly known by their initials, ATOs, in charge of coordinating the service at territorial level. However the current regulation has not yet determined which existing or new authorities are to take their place. Third, it is claimed that the price of water in Italy is one of the cheapest in Europe, but research results find that this is not sustainable in the long term (Utilitatis, 2011). In this context, efficiency is a necessary condition to guarantee this vital service in a fair and equal manner. The same concern is shared with previous studies carried out for other European countries, such as Spain and Portugal (González-Gómez et al., 2013; Da Cruz et al., 2012). Therefore the current study attempts to provide empirical results that can help policy makers and local governments in countries where the implementation of administrative reforms on ownership structure need to be made in a changing institutional environment and the pressure to provide a fair price for public services is high. 
The method applied in this paper combines two well-known nonparametric efficiency estimators-namely, Data Envelopment Analysis (DEA, Charnes et al., 1978) —with cluster analysis, following O'Donnell et al. (2008) and Balaguer-Coll et al. (2013). The advantage of using DEA is to rank water utilities on the basis of their efficiency score without requiring any assumption on the distribution function of the data (Rao et al., 2005). Moreover, by applying statistical clustering techniques the study controls for the effect of the 'moderators', which has not been carried out in previous studies.

The plan of the paper is as follows. Section 2 provide a brief overview of the studies regarding the efficiency of water utilities. Section 3 describes the regulatory framework of the Italian water supply service. Section 4 provides an explanation of the method and data. Section 5 reports the results and Section 6 concludes the paper.

\section{REVIEW OF THE RELEVANT LITERATURE}

Since the early 1970s, several studies have assessed the effect of ownership on water supply service (WSS) efficiency. These studies differ in several respects, including the method used to measure their efficiency levels. In particular, two groups of studies can be identified: those using accounting methods, and those applying econometrics and operational research methods. The current study applies an operational research method, namely DEA, to estimate WSS utility efficiency. As pointed out by Bogetoft and Otto (2011), the selection of a benchmarking approach should 'reflect and respect the characteristics of the industry'. With particular reference to the WSS, Berg and Marques (2011) argue that the lack of knowledge on the production function in this industry can justify the application of DEA. This method is considered more flexible than parametric approaches, since it does not require any assumption on the distribution function of the data. Moreover, Bogetoft (1994) highlighted the incentive-efficient properties of DEA that can be applied by regulators as it can be seen in England and Wales (Thanassoulis, 2000a,b).

The first study to apply the concept of Farrell (1957) efficiency-on which DEA is based-in this particular context was Byrnes et al. (1986), in an analysis focused on the US. The theoretical perspective on which the study was grounded provided arguments that privately-owned firms were more efficient than their publicly-owned counterparts. However, the nonparametric tests reveal no evidence that the latter utilities were 'more wasteful or operated with more slack than privately owned utilities' (Byrnes et al., 1986, p.341). Following and 'adjusting' Byrnes 
et al.'s (1986) method, several studies have applied DEA to analyse the relationship between ownership and water services' efficiency around the world. In line with the purpose of current study, the following review briefly outlines the research on the effect of ownership on WSS utility efficiency, classifying the studies into three groups according to their results: (i) studies that reported no influence of ownership on efficiency; (ii) studies finding that public ownership improves efficiency; and (iii) those finding better efficiency scores for privately owned utilities.

One of the most relevant contributions among the first group of studies would include Byrnes et al. (1986). More recent research includes García-Sánchez (2006), who measures the technical and scale efficiency of Spanish municipalities, distinguishing between those which externalised the water services to privately owned utilities and those which provide the service through public business corporations. The study claims that, in the specific context analysed, the creation of a quasi-market does not seem to affect efficiency. The author suggests that this result can be justified by the fact that the creation of public business corporations relieves the management of the business from the traditional public sector bureaucratic procedures. In this group of studies we also find Peda et al. (2013) who, in an application to Estonian water service utilities, found 'no difference in efficiency between water utilities with different types of ownership'. Their study also found a positive relationship between population size and efficiency, corroborating the hypothesis that efficiency gains are attributable to scale economies.

In the second group of studies, one of the most relevant contributions is the one by Romano and Guerrini (2011) on the efficiency of Italian water utilities. To the best of our knowledge, this is the first study to apply DEA to Italian water utilities, finding that publicly-owned utilities obtain higher efficiencies than mixed-owned. The authors interpret these results as an indication that publicly-owned utilities are better able to acquire and use their inputs. Moreover, the study considers the effect of size and geographical location on the performance of the water utilities. The results show the existence of economies of scale, since larger companies perform better. Regarding the geographical location issue, utilities located in Central and Southern Italy are more efficient than those operating in the north-although the differences were not statistically significant.

Finally, the third group of studies find superior performance in privately-owned utility firms. Specifically, Picazo-Tadeo et al. (2009) find that privately-owned utilities are more efficient than their publicly-owned counterparts. The authors claim that this result is due to efficiency in the use of labour, pointing out that the influence of trade unions makes it difficult to adjust the number of employees. González-Gómez et al. (2013), focusing on Spain's rural 
areas, find that both privately-owned utilities and public-private partnerships are significantly more efficient. Notably, the differences in term of efficiency between the three forms of ownership disappear when environmental variables are considered. As environmental variables the authors suggest the existence of economies of consumer density, the origin of water resources and the seasonality of demand. These are factors that can influence the efficiency but they do not depend on ownership structure. The authors concludes that public-owned utilities operate in a more challenging environment while private utilities avoid it due to low profitability expectations. The authors remark that public-private owned utilities do not perform badly in comparison with the other two kinds of utility ownership.

The available empirical evidence suggests that the debate on the links between ownership and performance is still unsettled. In addition, other variables also seem to be relevant in assessing performance and institutional choices. Firstly, the efficiency of water supply services can be related to their size, as the law of economies of scale would predict, however previous literature also suggests that economies of scale occur only after reaching certain level of output (Walter et al., 2009). Secondly, some studies highlight the effect of regulatory framework and incentive mechanisms on performance. González-Gómez and García-Rubio (2008) highlight that the greater efficiency observed for the private utilities could result from either the ownership features themselves or the regulatory framework within the industry. De Witte and Marques (2010) present a cross-country comparison examining the role of incentive mechanisms in relation to efficiency levels. The results show a positive effect of incentive mechanisms (such as benchmarking) on efficiency. On the basis of these results, the authors conclude that benchmarking could become a tool to create 'competition by comparison' in contrast to 'competition in the market' or 'competition for the market'. The importance of regulation, the creation of independent authorities to control the conduct of water utilities and benchmarking initiatives are also highlighted in recent research by Bel et al. (2015). This paper suggests these factors are essential in ensuring a fair water price, especially with respect to privatised utilities. Finally, efficiency can be affected by environmental variables, such the hydrographical characteristics of the geographical area in which the utilities are located (Martins et al., 2012).

The current research therefore attempts to contribute to this literature by investigating the effect of three variables, namely: ownership types, size and geographical location. These three variables are considered separately in the first stage of analysis and by combining their effects in the subsequent stage. This could shed light on the contribution of different ownership structures to assist in mitigating exogenous conditions such as hydrographical characteristics 
and aid in strategic planning on utilities size.

\section{WATER SERVICE IN ITALY}

Water supply services (WSS) are generally considered public services provided through a network regulated by public authorities, therefore any speculation on the organisation, governance and performance is strongly affected by the regulatory framework within each country. The Italian WSS are regulated by four hierarchical levels of jurisdiction: the European Union, the central government, the regional governments, and the local governments.

European legislation classifies water supply services as a 'service of general economic interest' (European Community Treaty, Article 86(2)). Therefore WSS are economic services that have to be provided to every citizen on a regular basis and at affordable prices, regardless of the ownership of the service provider. Moreover, in 2000 the European Commission issued the Water Framework Directive (WFD), addressing most of the challenges facing the management of this crucial resource. Two of the innovations introduced by the WFD were the cost recovery for water services and the 'polluter-pays' principles. These principles aim to create incentives for the sustainable and efficient use of water.

As highlighted in the previous section, the last decades have witnessed changes in the ownership of public service providers. The European Commission lets each Member State decide how it organises the provision of a service of general economic interest so long as the rules on both the internal market and competition are observed. As a result, different approaches to the organisation of WSS can be found among EU Member States. For instance, in The Netherlands and Germany, municipal public enterprises provide water services. Conversely, in England and Wales the service was totally privatised and a regulatory authority established (Bauby, 2012).

In Italy, water supply services were traditionally provided by municipalities. In this context, the service was financed via public budget, and the tariff was usually insufficient to cover the costs (Massarutto et al., 2008). In order to improve the efficiency of the industry, the Law 196/94 was enacted in 1994 to reform the industry. First, the reform recognised the network features of the WSS and introduced the concept of 'integrated water service', considering the whole water supply and sewage system. Second, the reform reorganised the WSS by introducing territorial authorities, ATOs, with the aim of exploiting economies of scale in the management of services. Regions were in charge of identifying these ATOs and municipalities could own equity shares in ATOs. About 90 ATOs were identified according to the political-administrative 
and hydrographical features of each area (Utilitatis, 2011). The main function assigned to the ATOs was to draw up a management plan for the WSS and to designate the WSS provider.

In the mid-2000s, Law 196/94 was replaced by the Environmental Code (Decree 152/2006), which retained the two main innovations of the previous law and introduced the European principle of cost recovery for the WSS. Among other norms, article 154 of the Environmental Code stated that the WSS price had to guarantee remuneration for the capital invested.

Meanwhile, changes had occurred in the institutional organisation of service providers. Since 1990, inspired by New Public Management, a series of reforms have been introduced to promote externalisation of local public services. The result is that the WSS provider could be a municipality, a municipal corporation, a mixed enterprise or a private entity. Moreover some municipalities have created municipal holdings that invested in private entity providing public service (Grossi and Mussari, 2009), therefore private entities can have a municipality as indirect shareholder.

Finally, water supply services were also affected by a series of relatively recent events. First, the financial crisis forced governments to cut their budgets. In this context, the Italian legislator suggested eliminating the ATOs by the end of 2011. However, this regulation did not determine which authority should replace the ATOs, a question that still remains unanswered. Second, in 2011 a referendum repealed article 23-bis of Law 113/2008 and article 154 of the Environmental Code. Subsequently, the appointment of the WSS is based only on European legislation, with the result that the service can be provided by municipalities directly, in house, by mixed enterprises without any specification of the percentage that must be owned by private partners, or by privately owned enterprises. A further consequence of the referendum was that the tariff should not be set according to the return on capital invested.

In conclusion, it can be argued that the main consequences of reforms and counter-reforms of the water supply services are: (i) a multilevel governance structure of the industry, although the levels of this structure are still uncertain regarding the replacement of the ATOs and the role of the regions; and (ii) in the absence of an intermediate authority such as the ATOs, it seems that municipalities could once again be free to choose the delivery mode and appoint the service provider as they did in the past; (iii) changes in the tariff computation, with particular regard to the return on capital invested. 


\section{METHODS AND DATA}

Our study investigates the effect of ownership and the 'moderators', i.e., size and geographical location, on the cost efficiency of Italian water utilities. To this end a three-stage methodology is applied: (i) we measure cost efficiency using a nonparametric estimators, namely, Data Envelopment Analysis (DEA); (ii) cluster analysis, building groups based on ownership, size and geographical allocation of the organisations; and (iii) testing for differences in the efficiencies in each group and each cluster-i.e., nonparametric test is applied to verify whether type of ownership, size, geographical location, or their combination in clusters result in significant efficiency differences.

This methodological approach is similar to the one considered by Balaguer-Coll et al. (2013) in studying the efficiency of Spanish municipalities. However it differs from previous relevant work on water utilities, such as (Peda et al., 2013; Romano and Guerrini, 2011), who considered an a priori classification of organizations, without considering the combined effect on performance. Therefore, the procedure carried out in this study allowed the definition of clusters ex-post instead of ex-ante identifying a combination of factors that can influence cost efficiency and controlling for heterogeneity.

For measuring cost efficiency we consider Data Envelopment Analysis (DEA). Its origins date back to Farrell's (1957) approach to frontier estimation, although it was not until 1978 that the term was first used (Charnes et al., 1978). Since then, this method has become one of the most popular techniques for benchmarking, with applications from financial firms to public service utilities-including water utilities (Fethi and Pasiouras, 2010).

DEA is a mathematical programming technique for the estimation of the best production frontier (or envelopment) and the measurement of the relative efficiency of different organisations (Bogetoft and Otto, 2011). This approach assigns a score between 0 and 1 to each decision making unit (in the case that an input orientation and Farrell distance functions are considered), allowing the organisations to be ranked on the basis of an increasing efficiency order. The term 'frontier' identifies the most efficient organisation that satisfies either the input or output-based Farrell efficiency condition.

In this study, efficiency measures are computed on the basis of two assumptions. Firstly efficiency scores are input-based and thus measure the level of input to obtain a given amount of output ${ }^{1}$. Secondly inputs are expressed in monetary terms allowing the measurement of

\footnotetext{
${ }^{1}$ As indicated by Rao et al. (2005), the input-oriented efficiency addresses the question: 'By how much can input quantities be proportionally reduced without changing the output quantities produced?' (Rao et al., 2005, p.137).
} 
cost efficiency.

Formally, the input-oriented DEA is based on the solution of the following linear programming problem (Rao et al., 2005; Coelli and Walding, 2006):

$$
\begin{array}{r}
\min _{\theta, \lambda} \theta \\
\text { s.t. } \\
y_{i}+Y \lambda \geq 0, \\
\theta x_{i}-X \lambda \geq 0, \\
N 1^{\prime} \lambda=1, \\
\lambda \geq 0 .
\end{array}
$$

where:

- $y_{i}$ is an $M \times 1$ vector of outputs produced by the $i^{\text {th }}$ firm,

- $Y$ is the $M \times N$ matrix of outputs of the $N$ firms in the sample,

- $X$ is the $K \times N$ matrix of inputs of the $N$ firms,

- $\lambda$ is an $N \times 1$ vector of weights (which relate to the peer firms) and $\theta$ is a scalar measure of efficiency, which takes a value between 0 and 1 (inclusive).

Further details on this approach are also available in Balaguer-Coll et al. (2007), among others, who propose a very similar program to the one followed in this paper. For a more comprehensive view, see also Cooper et al. (2007) and Färe et al. (1994).

\subsection{Testing for the equality of distributions of efficiency scores}

In the second stage of the analysis we try to ascertain whether the differences found among the efficiency scores of the firms in each group are statistically different or not. In this regard, a variety of instruments can be considered to test whether the differences between some of the moments that characterise two given distributions differ statistically. Some of these instruments are tests, such as the Wilcoxon test, which have the advantage of being relatively robust to the violation of the normality assumption but have the limitation of restraining the analysis to one moment of the distribution only (in our case, the distribution of efficiency scores), namely the

This approach seems particularly suitable for the context of the water industry, where utilities are more able to control their inputs rather than their outputs-such as water delivery and population served (Abbott and Cohen, 2009; Coelli and Walding, 2006; Romano and Guerrini, 2011). 
median. However, some recent applications (Balaguer-Coll et al., 2010) have considered some tools developed in the field of nonparametric statistics such as the Li (1996) test, which tests whether two distributions, not just two summary statistics such as the mean or the median, differ statistically.

\subsection{The sample}

As stated above, the empirical evidence presented in this paper focuses on a sample of water utilities operating in Italy from 2008 to 2011. A complete list of Italian water utilities was obtained from Federutilities, an Italian association of public services provider. ${ }^{2}$ However, the sample is restricted to mono-service utilities with available data and stable ownership structure. Therefore, only utilities for which the percentage of ownership has not changed from 2008 to 2011 are included in the analysis. The final sample is comprised of 68 utilities in each of the four years analysed, leading to 272 observations across the four years study (Table 1). The 68 utilities represent $70 \%$ of those listed by Federutilities and they served about $45 \%$ of the Italian population in 2011. Furthermore, utilities are classified according to three variables: ownership structure, size and geographical location.

As highlighted in the previous section, a water supply service provider could be a municipality, a municipal corporation, a municipal holding, a mixed enterprise or a private entity. In this scenario, our study focuses on water services which are externalised by the local government through a separate entity, namely an utility, with a different type of ownership structure. In our particular sample, five types of ownership were identified (Table 1). As demonstrated above, the conventional classification of private, public and mixed ownership used by previous research (Guerrini et al., 2011) does not fully reflect the complexity of the Italian context or any other national setting where many alternative modes to delivery public services coexist (Tavares and Camöes, 2007; Bel and Fageda, 2010). In addition to the utility ownership models of publicly owned (type 1) and privately owned (type 2), this research distinguishes between two specific groupings within mixed utilities. The first of these groups are utilities which have a public organisation as the controlling shareholder (type 3) and, the second group are utilities which have a private organisation as the controlling shareholder (type 4). Finally, we define a separate category of private utilities in which the indirect main shareholder is a public organisation (type 5). As reported in 132 utilities (128 observations over four years), corresponding to $47 \%$ of the sample, are publicly owned. The remaining utilities are primarily spread between

\footnotetext{
${ }^{2}$ In 2015 Federutilities was merged in Utilitalia.
} 
types 2 and 3. Only three utilities were classified as type 4 and six were classified as type 5 .

The size of water utilities is usually measured considering the population served, however, due to a lack of data over the time span analysed, a proxy was used in this study. A possible proxy is total revenue, obtained from utilities' financial statements. This variable shows a strong linear correlation with the population served (92\%), suggesting that revenue can be used as proxy of the population served with confidence. Table 1 shows that the sample is mainly characterised in small and medium size utilities, only three are considered to be large.

Finally, the third variable considered is geographical location. Most of the utilities in the sample are situated in the Northern of Italy, while $15 \%$ and $28 \%$ are in the Centre and Southern regions, respectively (Table 1). Italy is characterised by heterogeneous hydrographical features which can affect efficiency levels. Northern and Southern regions, saving a few exceptions, are characterized by surface waters that require a more sophisticated purification process, leading to higher operational and capital costs (Istat, 2008, 2014).

Utilities are further classified using cluster analysis in an the attempt to maximise the homogeneity of units within the clusters while maximising the heterogeneity among clusters. In the current analysis, five clusters are identified. The characteristics of these clasters are shown in Table 2 with their associated descriptions shown in Table 3. All variables were shown to be significant with regard to all clusters, with the exception of the fourth type of ownership mixed owned utilities with a private organisation that owns $50 \%$ or more. The cluster analysis discriminates between medium size, publicly owned utilities in central and Southern Italy (Cluster 1) and those that are located in the north of the country (Cluster 3). Cluster 2 contains both mixed and privately owned utilities however in both cases, the cluster analysis identifies the main direct or indirect shareholder as a public organisation and but does not discriminate between size and geographical location. Cluster 4 is characterised primarily by small sized, privately owned utilities located in Southern Italy. Finally, Cluster 5 aggregates primarily small sized, publicly owned and mixed owned utilities in Northern Italy.

Since we are using a data panel of 68 utilities from 2008 to 2011, a window analysis could also have been considered. However, we consider the approach used in this paper is appropriate due to the low likelihood of technical change in the short term in the context of the urban water sector. 


\subsection{Inputs and outputs}

One of the biggest challenges in the application of DEA was the selection of the input-output variables suitable and available for water utilities. Consistently with the aim to estimate cost efficiency scores, operational costs were used. Four operational costs were considered as inputs, namely: cost of materials, cost of services, cost of using third party resources (such as rented or leased plant and equipment), and wages.

The most popular measures of outputs are: the amount of water delivered, the population served, and the length of water mains (Coelli and Walding, 2006). The above data are not accessible for all the utilities in the sample and the population served is available only for 2011, therefore revenue is used as a proxy for the variable size.

Furthermore, since the analysis is longitudinal and both inputs and outputs are expressed in monetary terms, the data are deflated by the Italian consumer price index in order to correct them for inflation (Coelli and Walding, 2006). This adjustment is particularly relevant, since the time frame analysed is characterised by a considerable increase in prices $(5.5 \%)$.

Finally, Table 4 reports the definition of inputs and outputs, and Table 5 their corresponding descriptive statistics for each year under analysis. It is worthwhile noticing that skewness and kurtosis are far from zero, the value that indicates the variables under analysis follow a normal distribution.

\section{RESULTS}

\subsection{DEA efficiencies}

Efficiency scores for the utilities in the sample over the 4 years computed via DEA are reported in Tables 6 and 7. The tables report DEA efficiencies considering the three classification criteria both separately (Table 6) and jointly (Table 7).

When considering the ex-ante classifications (ownership, size, geographical location), remarkable differences are perceived among groups within each of the hypotheses considered. In the case of the groups constructed according to their ownership type, the discrepancies are particularly large. As indicated by the efficiency scores in Table 6, the discrepancies among average efficiencies are quite large, ranging from $49.19 \%$ for the most inefficient group (privately-owned utilities) to $90.42 \%$ for the least inefficient (privately-owned utilities with a public organisation as the main indirect shareholder). Focusing on the median, in order to isolate the effects of potential outliers, these discrepancies are even higher-the medians are $48.99 \%$ and $97.78 \%$ for 
these two groups, respectively.

When the 'moderators', i.e., size and geographical location, are considered separately, the results vary depending on the hypothesis considered. Regarding size, large firms show comparatively higher values-58.33\% of them are efficient (see Table 6), whereas small firms are quite inefficient by comparison as only $17.97 \%$ of such firms are efficient and the median is also quite low $(29.30 \%)$. This finding is consistent with previous research that indicated the existence of economies of scale in the water industry (Romano and Guerrini, 2011; Peda et al., 2013). In addition to this, the number of efficient firms for small, medium and large firms is $17.97 \%, 36.36 \%$ and $58.33 \%$, respectively, however this finding was partly to be expected given the assumption of variable returns to scale and the fact that the number of large firms is lower than the number of smaller firms.

The discrepancies are more modest when analysing results for groups based on their geographical location. The discrepancies among groups' average efficiencies are much lower (Table 6), and the utilities in the centre of Italy are the least inefficient, a finding that concurs with previous research (Romano and Guerrini, 2011).

\subsection{The 'moderators'}

As indicated in the introduction, understanding the link between ownership and performance may be particularly intricate due to the effects of 'moderators', among which Andrews et al. (2011) highlight the role of size, geographical location, and governance. This study combines these factors in a clusters to take into account their effect on efficiency.

The summary statistics for the efficiencies corresponding to the five groups identified by the cluster analysis are reported in Table 7 . The differences betare high, especially when comparing the least inefficient groups 2 (mixed ownership with both direct and indirect main public organisation as shareholder) and 3 (publicly owned, medium, in Northern Italy), with clusters 4 (privately owned, small, in Southern Italy) and 5 (publicly owned, small, in Southern Italy).

More specifically, the average efficiencies corresponding to groups 2 and 3 are particularly high $(81.29 \%$ and $86.26 \%$, respectively), analogously to the values for the medians $(93.99 \%$ and $97.16 \%$, respectively). In contrast, the behaviour is quite the opposite for clusters 4 and 5, whose medians are $52.78 \%$ and $24.93 \%$, which suggests that the mix of privately owned and small firms in Southern Italy may be particularly problematic in terms of efficiency. This finding seems to emphasise the relevance of economies of scale and the importance of public investment in the water industry, especially in areas where the purification process needs to be 
more intense, such as in the southern parts of the country.

\subsection{Testing for the differences among WSS efficiency scores}

The analysis in the above paragraphs is based on soley summary statistics and its statistical precision is therefore limited. In this section the methods proposed in section 4.1 are applied to test whether the differences among the efficiencies of firms in the groups formed according to different criteria are significant or not. The method employed, as indicated in section 4.1, has the interesting virtue that it does not compare summary statistics but entire distributions of efficiency, as well as being fully nonparametric (and, therefore, consistent with the nonparametric DEA estimators).

This test compares the densities, estimated via kernel smoothing, for the unconditioned and conditioned relative series of efficiencies, where the unconditioned relative efficiency series corresponds to each firm's efficiency, divided by the average corresponding to all firms (computed yearly), and the conditioned relative efficiency series corresponds to each firm's efficiency divided by its group average. This average will differ depending on the hypothesis considered-ownership, size, geographical location or their combined effect.

The densities are displayed in Figure 1. The lines in each sub-figure correspond to the unconditioned (solid line) and conditioned (dashed lines) relative efficiency series. Regardless of whether the series is unconditioned or conditioned, the amount of multi-modality is remarkable, with pronounced modes well below the mean (which is 1, given we are dividing by the mean). This suggests there are non-negligible pockets of inefficient behaviour which do not vanish after controlling for our three factors-or their combined effects.

If the conditioning results in tighter densities and closer to the mean (i.e., unity), this would indicate that the conditioning scheme considered is relevant, i.e., efficiencies for all utility firms in the same group would be similar. This is only the case when conditioning for size and, to a lesser extent, ownership, whereas the effect of geography is negligible as the densities almost overlap. The combined effect (the 'moderators') shows the strongest effect, as densities shift leftwards, approaching the mean (see Figure 1.d), corroborating the descriptive analysis carried out in the previous section.

Li's (1996) test provides statistical evidence to support this visual analysis. Results, shown

in Table 8, corroborate the analysis stemming from the visual inspection of the densities, since differences are particularly significant when considering size alone, or the combined effect of the three hypotheses. In contrast, geographical location the differences does not produce 
significant differences, whereas in the case of the type of ownership the effect is only significant at the $5 \%$ significance level.

\section{CONCLUSIONS}

This paper foucuses on a key public service, water supply services, and purpose of this study has been to analyse the influence of local public ownership on the efficiency of Italian water utilities. The study was motivated by the puzzling relationship between the different types of ownership and efficiency. In addition, the literature has identified a gap in understanding the effect of 'moderators' on the performance of water supply services.

We have considered the case of Italy, where these services have traditionally been provided by local governments but changes in regulation and the acceptance of paradigms such as New Public Management have resulted in such services being provided by different organisations. The current study has gone beyond the conventional classification of three ownership types (public, private and mixed), identifying five types of ownership and better reflecting the complexity of public service organisation in Italy and other countries. In this context, the relationship between types of ownership and efficiency is further involved due to the disparate sizes and geographical locations of the utilities. Previous studies have considered the effect of ownership type, geographical location and size in isolation, whereas this study explores the combined effect of these three factors on efficiency simultaneously.

From a methodological point of view, it can be argued that cluster analysis and appropriate nonparametric tests help to better discriminate among the different factors that can affect the efficiency of water utilities. Specifically, we measure efficiency by applying Data Envelopment Analysis and tests based on kernel smoothing to ascertain whether the differences between the clusters were significant or not. Using these methods the current study has found statistically significant differences in efficiencies across ownership types. Even stronger results were seen when considering groups based on size or the groups yielded by cluster analysis, which combine all the three factors of ownership type, size and geographical characteristics.

Furthermore the results suggest that privately owned utilities which are indirectly controlled by public organisations reach the highest level of efficiency when size and geographical location are not considered. However, the combined effect of ownership, size and geographical location has a stronger effect on efficiency. In this case, mixed-owned water utilities, in which a public organisation has direct or indirect control, are those with the higher efficiency levels. 
Our results suggests that policy makers and regulators should carefully consider the intrinsic characteristics of each industry in order to achieve better performance for public services. In particular, with respect to the water industry, both public-private partnerships and economies of scale seem to be important aspects to take into consideration, particularly when evaluating them simultaneously.

Finally, we draw attention to the need to broaden this line of research to improve the likely implications for regulators and policy makers. Although ownership and efficiency are important dimensions which affect the 'publicness' and performance, a comprehensive analysis would require to simultaneously consider the impact of 'control','funding' and 'change' on efficiency, effectiveness and equity (Andrews et al., 2011; Bowles et al., 2005; Bozeman, 1987). In a recent paper, (Bel et al., 2015) consider the effect of market concentrations on water service prices. The paper point outs that economies of scale are usually positively associated with efficiency, however the market has become highly concentrated and the lack of adequate regulation results in an increase of water prices. Such a situation is characterised by a trade-off between efficiency and equity, underlining the need for further, more encompassing research. 


\section{References}

Abbott, M. and Cohen, B. (2009). Productivity and Efficiency in the Water Industry. Utilities Policy, 17(3):233-244.

Andrews, R., Boyne, G. A., and Walker, R. M. (2011). Dimensions of Publicness and Organizational Performance: A Review of the Evidence. Journal of Public Administration Research and Theory, 21(suppl 3):i301-i319.

Balaguer-Coll, M. T., Prior, D., and Tortosa-Ausina, E. (2007). On the determinants of local government performance: A two-stage nonparametric approach. European Economic Review, 51(2):425-451.

Balaguer-Coll, M. T., Prior, D., and Tortosa-Ausina, E. (2010). Devolution Dynamics of Spanish Local Government. Environment and Planning A, 42(6):1476-1495.

Balaguer-Coll, M. T., Prior, D., and Tortosa-Ausina, E. (2013). Output Complexity, Environmental Conditions, and the Efficiency of Municipalities. Journal of Productivity Analysis, 39(3):303-324.

Bauby, P. (2012). Local Services of General Economic Interest in Europe. Water Services: What Are the Challenges? Annals of Public and Cooperative Economics, 83(4):561-583.

Bel, G., Brown, T., and Warner, M. (2014). Editorial Overview: Symposium on Mixed and Hybrid Models of Public Service Delivery. International Public Management Journal, 17(3):297-307.

Bel, G. and Fageda, X. (2010). Partial Privatisation in Local Services Delivery: An Empirical Analysis of the Choice of Mixed Firms. Local Government Studies, 36(1):129-149.

Bel, G., Fageda, X., and Warner, M. E. (2010). Is Private Production of Public Services Cheaper Than Public Production? A Meta-regression Analysis of Solid Waste and Water Services. Journal of Policy Analysis and Management, 29(3):553-577.

Bel, G., González-Gómez, F., and Picazo-Tadeo, A. J. (2015). Does Market Concentration Affect Prices in the Urban Water Industry? Environment and Planning C: Government and Policy, 33(6):1546-1565.

Berg, S. and Marques, R. (2011). Quantitative Studies of Water and Sanitation Utilities: A Literature Survey. Water Policy, 13(5):591-606.

Bogetoft, P. (1994). Incentive Efficient Production Frontiers: An Agency Perspective on DEA. Management Science, 40(8):959-968.

Bogetoft, P. and Otto, L. (2011). Benchmarking with DEA, SFA, and R. Springer, New York.

Bowles, S., Edwards, R., and Roosevelt, F. (2005). Understanding Capitalism: Competition, Command and Change. Oxford University Press, Cambridge, MA. 
Bozeman, B. (1987). All Organizations are Public: Bridging Public and Private Organization Theories. JosseyBass, San Francisco.

Byrnes, P., Grosskopf, S., and Hayes, K. (1986). Efficiency and Ownership: Further Evidence. Review of Economics and Statistics, 68(2):337-341.

Charnes, A., Cooper, W. W., and Rhodes, E. (1978). Measuring the efficiency of decision making units. European Journal of Operational Research, 2(6):429-444.

Coelli, T. and Walding, S. (2006). Performance Measurement and Regulation of Network Utilities, chapter Performance Measurement in the Australian Water Supply Industry: A Preliminary Analysis, pages 29-62. Edward Elgar, Cheltenham, UK.

Cooper, W. W., Seiford, L. M., and Tone, K. (2007). Introduction to Data Envelopment Analysis and Its Uses. With DEA-Solver Software and References. Springer, New York.

Da Cruz, N. F., Marques, R. C., Romano, G., and Guerrini, A. (2012). Measuring the efficiency of Water Utilities: A Cross-national Comparison Between Portugal and Italy. Water Policy, 14(5):841-853.

De Witte, K. and Marques, R. C. (2010). Designing Performance Incentives, An International Benchmark Study in the Water Sector. Central European Journal of Operations Research, 18(2):189-220.

Demsetz, H. (1967). Toward a Theory of Property Rights. The American Economic Review, 57(2):347-359.

Farrell, M. J. (1957). The Measurement of Productive Efficiency. Journal of the Royal Statistical Society. Series A (General), 120(3):253-290.

Fethi, M. D. and Pasiouras, F. (2010). Assessing Bank Efficiency and Performance with Operational Research and Artificial Intelligence Techniques: A Survey. European Journal of Operational Research, 204(2):189-198.

Färe, R., Grosskopf, S., and Lovell, C. A. K. (1994). Production Frontiers. Cambridge University Press, Cambridge.

García-Sánchez, I. M. (2006). Efficiency Measurement in Spanish Local Government: The Case of Municipal Water Services. Review of Policy Research, 23(2):355-372.

González-Gómez, F., García-Rubio, M. A., Alcalá-Olid, F., and Ortega-Díaz, M. I. (2013). Outsourcing and Efficiency in the Management of Rural Water Services. Water Resources Management, 27(3):731-747.

González-Gómez, F. J. and García-Rubio, M. Á. (2008). Efficiency in the Management of Urban Water Services. What Have We Learned After Four Decades of Research? Hacienda Pública Española, 185(2):39-67. 
Grossi, G. and Mussari, R. (2009). The Effects of Corporatisation on Financial Reporting: The Experience of the Italian Local Governments. International Journal of Public Policy, 4(3-4):268-282.

Guerrini, A., Romano, G., and Campedelli, B. (2011). Factors Affecting the Performance of Water Utility Companies. International Journal of Public Sector Management, 24(6):543-566.

Guy, S., Graham, S., and Marvin, S. (1996). Privatized Utilities and Regional Governance: The New Regional Managers? Regional Studies, 30(8):733-739.

Hart, O. and Moore, J. (1990). Property rights and the nature of the firm. Journal of political economy, 98(6):1119-1158.

Hood, C. (1991). A Public Management For All Seasons? Public Administration, 69(1):3-19.

Istat (2008). Censimento delle Risorse Idriche a Uso Civile [Survey on Domestic Water Use]. Technical report, Istituto Nazionale di Statistica.

Istat (2014). Censimento delle Risorse Idriche a Uso Civile [Survey on Domestic Water Use]. Technical report, Istituto Nazionale di Statistica.

Li, Q. (1996). Nonparametric Testing of Closeness Between Two Unknown Distribution Functions. Econometric Reviews, 15(3):261-274.

Martins, R., Coelho, F., and Fortunato, A. (2012). Water Losses and Hydrographical Regions Influence on the Cost Structure of the Portuguese Water Industry. Journal of Productivity Analysis, 38(1):81-94.

Massarutto, A., Paccagnan, V., and Linares, E. (2008). Private Management and Public Finance in the Italian Water Industry: A Marriage of Convenience? Water Resources Research, 44(12):1-17.

Niskanen, W. A. (1971). Bureaucracy and Representative government. Transaction Publishers, New Jersey.

O'Donnell, C. J., Rao, D. S. P., and Battese, G. E. (2008). Metafrontier Frameworks for the Study of Firm-level Efficiencies and Technology Ratios. Empirical Economics, 34(2):231-255.

Osborne, D. and Gaebler, T. (1992). Reinventing Government: How the Entrepreneurial Spirit is Transforming the Public Sector. Addison-Wesley, Reading, MA.

Peda, P., Grossi, G., and Liik, M. (2013). Do Ownership and Size Affect the Performance of Water Utilities? Evidence from Estonian Municipalities. Journal of Management \& Governance, 17(2):237-259.

Picazo-Tadeo, A. J., González-Gómez, F., and Sáez-Fernández, F. J. (2009). Accounting for Operating Environments in Measuring Water Utilities' Managerial Efficiency. The Service Industries Journal, 29(6):761-773.

Pollitt, C. and Bouckaert, G. (2011). Public Management Reform: A Comparative Analysis - New Public Management, Governance, and the Neo-Weberian State. Oxford University Press, Oxford. 
Rao, D. P., O'Donnell, C. J., Battese, G. E., and Coelli, T. J. (2005). An Introduction to Efficiency and Productivity Analysis. Springer, New York.

Romano, G. and Guerrini, A. (2011). Measuring and Comparing the Efficiency of Water Utility Companies: A Data Envelopment Analysis Approach. Utilities Policy, 19(3):202-209.

Savas, E. S. (2000). Privatization and Public-Private Partnerships. Chatham House, New York.

Shaw, P. G. and Munday, M. (1999). Regional Winners and Losers From Recent Trends in Utility Rationalization. Regional Studies, 33(8):769-778.

Sheather, S. J. and Jones, M. C. (1991). A Reliable Data-based Bandwidth Selection Method for Kernel Density Estimation. Journal of the Royal Statistical Society, Ser.B,53(3):683-690.

Tavares, A. F. and Camöes, P. J. (2007). Local Service Delivery Choices in Portugal: A Political Transaction Costs Framework. Local Government Studies, 33(4):535-553.

Thanassoulis, E. (2000a). DEA and Its Use in the Regulation of Water Companies. European Journal of Operational Research, 127(1):1-13.

Thanassoulis, E. (2000b). The Use of Data Envelopment Analysis in the Regulation of UK Water Utilities: Water Distribution. European Journal of Operational Research, 126(2):436-453.

Utilitatis (2011). Blue book 2011. Technical report, Utilitatis, Rome.

Vining, A. R. and Weimer, D. L. (Forthcoming). The Challenges of Fractionalized Property Rights in Public-Private Hybrid Organizations: The Good, the Bad, and the Ugly. Regulation \& Governance.

Walter, M., Cullmann, A., von Hirschhausen, C., Wand, R., and Zschille, M. (2009). Quo Vadis Efficiency Analysis of Water Distribution? A Comparative Literature Review. Utilities Policy, 17(3):225-232.

Warner, M. E. and Hefetz, A. (2008). Managing Markets for Public Service: The role of Mixed PublicPrivate Delivery of City Services. Public Administration Review, 68(1):155-166.

Williamson, O. E. (1979). Transaction-cost Economics: The Governance of Contractual Relations. Journal of Law and Economics, 22(2):233-261.

Williamson, O. E. (1999). Public and Private Bureaucracies: A Transaction Cost Economics Perspective. Journal of Law, Economics, \& Organization, 15(1):306-342. 
Table 1: Italian water service utilities, distribution according to ownership, size and geographical location

\begin{tabular}{|c|c|c|c|}
\hline Ownership & \# & \# & $\%$ \\
\hline Publicly owned utilities (ownership type 1) & 32 & 128 & $47 \%$ \\
\hline Privately owned utilities (ownership type 2) & 15 & 60 & $22 \%$ \\
\hline Mixed owned utilities with public organisation that owns 50\% or more (ownership type 3 ) & 12 & 48 & $18 \%$ \\
\hline Mixed owned utilities with private organisation that owns $50 \%$ or more (ownership type 4 ) & 3 & 12 & $4 \%$ \\
\hline Privately owned utilities with main a public organisation as indirect shareholder (ownership type 5) & 6 & 24 & $9 \%$ \\
\hline Total & 68 & 272 & $100 \%$ \\
\hline Size & $\#$ & $\#$ & $\%$ \\
\hline Small & 32 & 128 & $47.1 \%$ \\
\hline Medium & 33 & 132 & $48.5 \%$ \\
\hline Large & 3 & 12 & $4.4 \%$ \\
\hline Total & 68 & 272 & $100 \%$ \\
\hline Geographical Location & $\#$ & $\%$ & \\
\hline North & 39 & 156 & $57.4 \%$ \\
\hline Centre & 10 & 40 & $14.7 \%$ \\
\hline South & 19 & 76 & $27.9 \%$ \\
\hline Total & 68 & 272 & $100 \%$ \\
\hline
\end{tabular}


Table 2: Italian water service utilities, characteristics of the clusters based on ownership, size and geographical location ${ }^{a}$

\begin{tabular}{|c|c|c|c|c|c|c|c|c|c|c|c|}
\hline \multirow{2}{*}{ Variables } & \multirow{2}{*}{ Categories } & \multicolumn{2}{|c|}{ Cluster 1} & \multicolumn{2}{|c|}{ Cluster 2} & \multicolumn{2}{|c|}{ Cluster 3} & \multicolumn{2}{|c|}{ Cluster 4} & \multicolumn{2}{|c|}{ Cluster 5} \\
\hline & & $\#$ & $\%$ & $\#$ & $\%$ & $\#$ & $\%$ & $\#$ & $\%$ & $\#$ & $\%$ \\
\hline \multirow{5}{*}{ Ownership } & $\begin{array}{l}\text { Publicly owned utili- } \\
\text { ties }\end{array}$ & 13 & $100 \%$ & 0 & $0 \%$ & 11 & $100 \%$ & 0 & $0 \%$ & 8 & $44 \%$ \\
\hline & $\begin{array}{l}\text { Privately owned util- } \\
\text { ities }\end{array}$ & 0 & $0 \%$ & 2 & $13 \%$ & 0 & $0 \%$ & 10 & $91 \%$ & 3 & $17 \%$ \\
\hline & $\begin{array}{l}\text { Mixed owned utili- } \\
\text { ties with public or- } \\
\text { ganisation that owns } \\
50 \% \text { or more }\end{array}$ & 0 & $0 \%$ & 6 & $40 \%$ & 0 & $0 \%$ & 1 & $9 \%$ & 5 & $28 \%$ \\
\hline & $\begin{array}{l}\text { Mixed owned utili- } \\
\text { ties with private or- } \\
\text { ganisation that owns } \\
50 \% \text { or more }\end{array}$ & 0 & $0 \%$ & 2 & $13 \%$ & 0 & $0 \%$ & 0 & $0 \%$ & 1 & $6 \%$ \\
\hline & $\begin{array}{l}\text { Privately owned util- } \\
\text { ities with public or- } \\
\text { ganisation as main } \\
\text { indirect shareholders }\end{array}$ & 0 & $0 \%$ & 5 & $33 \%$ & 0 & $0 \%$ & 0 & $0 \%$ & 1 & $6 \%$ \\
\hline \multirow{3}{*}{ Size } & Small & 3 & $23 \%$ & 0 & $0 \%$ & 0 & $0 \%$ & 11 & $100 \%$ & 18 & $100 \%$ \\
\hline & Medium & 7 & $54 \%$ & 15 & $100 \%$ & 11 & $100 \%$ & 0 & $0 \%$ & 0 & $0 \%$ \\
\hline & Large & 3 & $23 \%$ & & $0 \%$ & & $0 \%$ & & $0 \%$ & & $0 \%$ \\
\hline \multirow{3}{*}{ Geographical location } & Northern Italy & 1 & $8 \%$ & 9 & $60 \%$ & 11 & $100 \%$ & 0 & $0 \%$ & 18 & $100 \%$ \\
\hline & Central Italy & 5 & $38 \%$ & 5 & $33 \%$ & 0 & $0 \%$ & 0 & $0 \%$ & 0 & $0 \%$ \\
\hline & Southern Italy & 7 & $54 \%$ & 1 & $7 \%$ & 0 & $0 \%$ & 11 & $100 \%$ & 0 & $0 \%$ \\
\hline \multicolumn{2}{|c|}{ \# of utilities in the cluster } & 13 & $100 \%$ & 15 & $100 \%$ & 11 & $100 \%$ & 11 & $100 \%$ & 18 & $100 \%$ \\
\hline
\end{tabular}


Table 3: Description of the clusters

\begin{tabular}{|c|c|c|c|}
\hline Cluster & Description & $\begin{array}{l}\text { \# of firms in the } \\
\text { cluster }\end{array}$ & $\begin{array}{c}\% \text { of the total } \\
\text { number of firms }\end{array}$ \\
\hline Cluster 1 & Publicly owned, medium-large, in Central-Southern Italy & 13 & $19 \%$ \\
\hline Cluster 2 & Mixed owned with both direct and indirect main public organisation as shareholder & 15 & $22 \%$ \\
\hline Cluster 3 & Publicly owned, medium, in Northern Italy & 11 & $16 \%$ \\
\hline Cluster 4 & Privately owned, small, in Southern Italy & 11 & $16 \%$ \\
\hline Cluster 5 & Publicly owned and mixed owned utilities, small, in Northern Italy & 18 & $26 \%$ \\
\hline Total & & 68 & $100 \%$ \\
\hline
\end{tabular}


Table 4: Definition of inputs and outputs

\begin{tabular}{lll}
\hline Variable & Variable name & Description \\
\hline Output & & \\
\hline$y_{1}$ & Total revenue & Accrued revenue recorded in the income statement \\
\hline Inputs & & \\
\hline$x_{1}$ & Cost of materials & Accrued cost of raw material recorded in the income statement \\
$x_{2}$ & Cost of labour & Accrued cost of labor recorded in the income statement \\
$x_{3}$ & Cost of services & Accrued cost of services recorded in the income statement \\
$x_{4}$ & Cost of leases & Accrued cost of rented asset and in operating leasing recorded in the income statement \\
\hline
\end{tabular}


Table 5: Italian water service utilities, descriptive statistics for inputs and outputs $^{\mathrm{a}}$

\begin{tabular}{clrrrrr}
\hline Year & Variable & Mean & Std. dev. & Median & Skewness & Kurtosis \\
\hline \multirow{4}{*}{ Year 2011 } & $y_{1}$ & $10,121,335$ & $16,988,394$ & $2,348,111$ & 2.7 & 8.5 \\
\cline { 2 - 7 } & $x_{1}$ & $1,083,785$ & $3,111,111$ & 193,655 & 6.4 & 45.2 \\
& $x_{2}$ & $1,738,548$ & $3,050,778$ & 446,292 & 2.9 & 9.5 \\
& $x_{3}$ & $4,405,616$ & $7,292,794$ & $1,016,890$ & 2.3 & 5.1 \\
& $x_{4}$ & $1,215,181$ & $5,526,878$ & 56,840 & 7.4 & 55.7 \\
\cline { 2 - 7 } Year 2010 & $y_{1}$ & $10,043,699$ & $17,009,684$ & $2,403,003$ & 2.9 & 10.4 \\
\cline { 2 - 7 } & $x_{1}$ & $1,078,828$ & $2,853,741$ & 214,342 & 6.0 & 40.5 \\
& $x_{2}$ & $1,645,831$ & $2,794,543$ & 500,416 & 3.1 & 12.1 \\
& $x_{3}$ & $4,027,370$ & $6,293,973$ & 973,705 & 2.1 & 4.5 \\
& $x_{4}$ & 655,829 & $1,302,237$ & 37,137 & 2.2 & 3.6 \\
\cline { 2 - 7 } Year 2009 & $y_{1}$ & $10,024,592$ & $16,372,146$ & $2,776,805$ & 2.5 & 7.4 \\
\cline { 2 - 7 } & $x_{1}$ & $1,006,826$ & $2,778,297$ & 219,541 & 6.1 & 42.1 \\
& $x_{2}$ & $1,751,179$ & $3,107,051$ & 527,256 & 3.2 & 12.2 \\
& $x_{3}$ & $4,298,332$ & $6,879,418$ & 966,142 & 2.2 & 4.7 \\
& $x_{4}$ & 674,433 & $1,408,328$ & 29,394 & 2.4 & 4.5 \\
\cline { 2 - 7 } & $y_{1}$ & $9,674,737$ & $16,020,107$ & $3,014,006$ & 2.7 & 8.2 \\
\cline { 2 - 6 } Year 2008 & $x_{1}$ & $1,061,385$ & $3,181,462$ & 202,686 & 6.6 & 47.2 \\
& $x_{2}$ & $1,714,371$ & $3,172,536$ & 473,426 & 3.5 & 14.9 \\
& $x_{3}$ & $4,354,073$ & $7,209,273$ & $1,060,797$ & 2.3 & 5.0 \\
& $x_{4}$ & 676,034 & $1,443,635$ & 32,759 & 2.5 & 5.7 \\
\hline
\end{tabular}

${ }^{a}$ In thousands of $€$. 
Table 6: DEA efficiency scores for Italian water service utilities, distribution according to ownership, size and geographical location

\begin{tabular}{lllrrrrr}
\hline Classification & Group & Mean & $\mathbf{1}^{\text {st }}$ quartile & Median & 3 $^{\text {rd }}$ quartile & Std.dev. & \% efficient firms \\
\hline \multirow{4}{*}{ Ownership } & Type 1 & 0.6567 & 0.3149 & 0.7587 & 1.0000 & 0.3404 & 26.56 \\
& Type 2 & 0.4919 & 0.1532 & 0.4899 & 0.8770 & 0.3634 & 21.67 \\
& Type 3 & 0.6397 & 0.2076 & 0.7183 & 1.0000 & 0.3781 & 39.58 \\
& Type 4 & 0.5774 & 0.2890 & 0.5375 & 0.8670 & 0.3033 & 16.67 \\
& Type 5 & 0.9042 & 0.8035 & 0.9778 & 1.0000 & 0.1224 & 41.67 \\
\hline \multirow{3}{*}{ Size } & Small & 0.4572 & 0.1416 & 0.2930 & 0.7944 & 0.3584 & 17.97 \\
& Medium & 0.7818 & 0.6717 & 0.8737 & 1.0000 & 0.2656 & 36.36 \\
& Large & 0.9311 & 0.8871 & 1.0000 & 1.0000 & 0.1196 & 58.33 \\
\hline \multirow{3}{*}{ Geography } & North & 0.6371 & 0.2451 & 0.7382 & 1.0000 & 0.3483 & 28.21 \\
& Centre & 0.7115 & 0.4676 & 0.9037 & 1.0000 & 0.3651 & 35.00 \\
\hline \multirow{2}{*}{ Total } & South & 0.5929 & 0.2073 & 0.6001 & 1.0000 & 0.3518 & 26.32 \\
\hline
\end{tabular}


Table 7: DEA efficiency scores for Italian water service utilities, distribution according to clusters

\begin{tabular}{lllrrrrr}
\hline Classification & Group & Mean & $\mathbf{1}^{\text {st }}$ quartile & Median & $3^{\text {rd }}$ quartile & Std.dev. & \% efficient firms \\
\hline \multirow{4}{*}{ Clusters } & Cluster 1 & 0.6366 & 0.3786 & 0.7589 & 0.9142 & 0.3407 & 19.23 \\
& Cluster 2 & 0.8129 & 0.7198 & 0.9399 & 1.0000 & 0.2555 & 41.67 \\
& Cluster 3 & 0.8626 & 0.7514 & 0.9716 & 1.0000 & 0.1862 & 47.73 \\
& Cluster 4 & 0.5161 & 0.1532 & 0.5278 & 0.9687 & 0.3729 & 25.00 \\
\hline \multirow{2}{*}{ Total } & Cluster 5 & 0.4216 & 0.1423 & 0.2493 & 0.6648 & 0.3425 & 15.28 \\
\hline
\end{tabular}


Table 8: Testing the closeness between unconditioned and conditioned relative efficiency series (Li, 1996)

\begin{tabular}{lrr}
\hline & \multicolumn{2}{c}{ DEA } \\
Null hypothesis & $T$-statistic & $p$-value \\
\hline$H_{0}: f($ Unconditioned $)=g($ Ownership-conditioned $)$ & 2.1631 & 0.0153 \\
$H_{0}: f($ Unconditioned $)=g($ Size-conditioned $)$ & 26.1374 & 0.0000 \\
$H_{0}: f$ (Unconditioned $)=g($ Geographical location-conditioned $)$ & -1.0027 & 0.8420 \\
$H_{0}: f($ Unconditioned $)=g($ Combined effect $)$ & 22.5473 & 0.0000 \\
\hline
\end{tabular}


Figure 1: Kernel density plots of the unconditioned vs. conditioned efficiencies, DEA

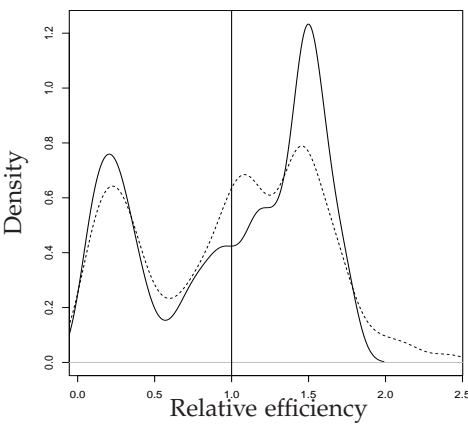

a) Unconditioned vs. ownership-conditioned

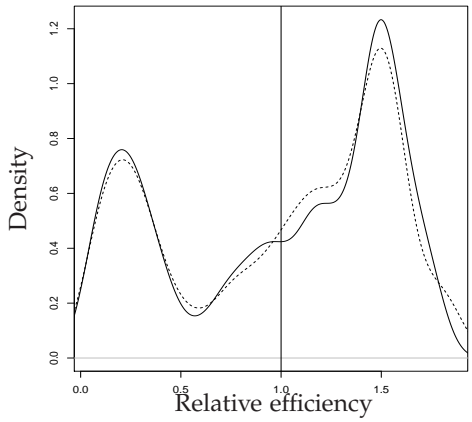

c) Unconditioned vs. geography-conditioned

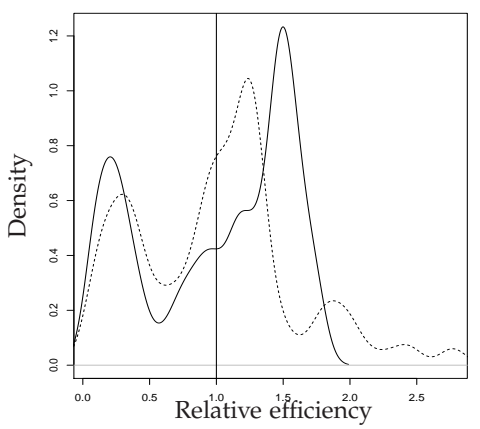

b) Unconditioned vs. size-conditioned

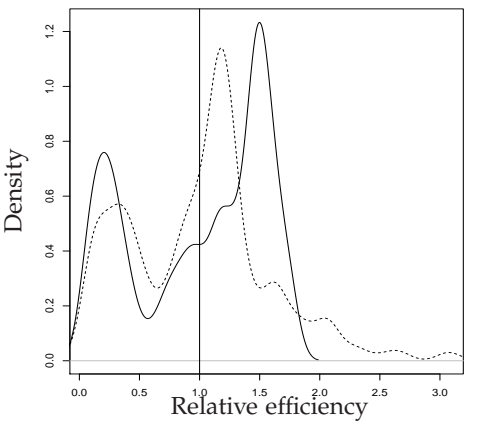

d) Unconditioned vs. clusters-conditioned

\section{Unconditioned}

Conditioned

Notes: All figures contain densities estimated using kernel smoothing for unconditioned and conditioned DEA efficiency scores. The vertical lines in each plot represent the average for all series, since we divide by the corresponding (group) mean. A Gaussian kernel and the Sheather and Jones (1991) plug-in bandwidth were chosen. 